\title{
Toward mimicking the bone structure: design of novel hierarchical scaffolds with a tailored radial porosity gradient
}

Citation for published version (APA):

Di Luca, A., Longoni, A., Criscenti, G., Mota, C., van Blitterswijk, C., \& Moroni, L. (2016). Toward

mimicking the bone structure: design of novel hierarchical scaffolds with a tailored radial porosity gradient. Biofabrication, 8(4), [045007]. https://doi.org/10.1088/1758-5090/8/4/045007

Document status and date:

Published: 01/12/2016

DOI:

10.1088/1758-5090/8/4/045007

Document Version:

Publisher's PDF, also known as Version of record

\section{Document license:}

Taverne

Please check the document version of this publication:

- A submitted manuscript is the version of the article upon submission and before peer-review. There can be important differences between the submitted version and the official published version of record.

People interested in the research are advised to contact the author for the final version of the publication, or visit the DOI to the publisher's website.

- The final author version and the galley proof are versions of the publication after peer review.

- The final published version features the final layout of the paper including the volume, issue and page numbers.

Link to publication

\footnotetext{
General rights rights.

- You may freely distribute the URL identifying the publication in the public portal. please follow below link for the End User Agreement:

www.umlib.nl/taverne-license

Take down policy

If you believe that this document breaches copyright please contact us at:

repository@maastrichtuniversity.nl

providing details and we will investigate your claim.
}

Copyright and moral rights for the publications made accessible in the public portal are retained by the authors and/or other copyright owners and it is a condition of accessing publications that users recognise and abide by the legal requirements associated with these

- Users may download and print one copy of any publication from the public portal for the purpose of private study or research.

- You may not further distribute the material or use it for any profit-making activity or commercial gain

If the publication is distributed under the terms of Article $25 \mathrm{fa}$ of the Dutch Copyright Act, indicated by the "Taverne" license above, 
PAPER

\section{Toward mimicking the bone structure: design of novel hierarchical scaffolds with a tailored radial porosity gradient}

To cite this article: Andrea Di Luca et al 2016 Biofabrication 8045007

View the article online for updates and enhancements.

\section{Related content}

- Surface energy and stiffness discrete
$\frac{\text { gradients in additive manufactured }}{\text { scaffolds for osteochondral regeneration }}$
Andrea Di Luca, Alessia Longoni,
Giuseppe Criscenti et al.
- Triphasic scaffolds for the regeneration of
$\frac{\text { the bone-ligament interface }}{\text { G Criscenti, A Longoni, A Di Luca et al. }}$
- Additive manufactured polymeric 3D
$\frac{\text { scaffolds with tailored surface topography }}{\text { influence mesenchymal stromal cells }}$
$\frac{\text { activity }}{\text { Sara C Neves, Carlos Mota, Alessia }}$
Longoni et al.

\section{Recent citations}

- $\underline{\text { Crosstalk between Bone and Nerves }}$
Qianin Bone
- $\frac{\text { Rapid conversion of highly porous borate }}{\text { glass microspheres into hydroxyapatite }}$
Md Towhidul Islam et al
- Andrea Roberto Calore et al

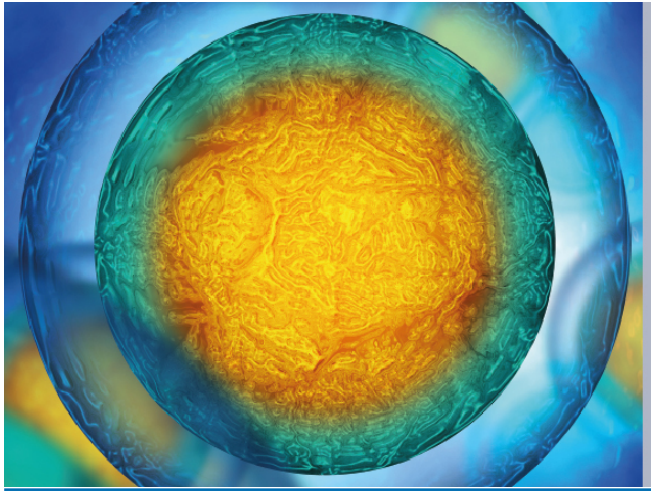

Biophysical Society $\quad$ IOP $\mid$ ebooks $^{\text {'m }}$

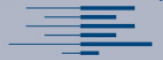

Your publishing choice in all areas of biophysics research

Start exploring the collection-download the first chapter of every title for free. 


\title{
Biofabrication
}

\section{PAPER}

CrossMark

\section{Toward mimicking the bone structure: design of novel hierarchical scaffolds with a tailored radial porosity gradient}

15 June 2016

REVISED

21 August 2016

ACCEPTED FOR PUBLICATION

2 September 2016

PUBLISHED

10 October 2016

\author{
Andrea Di Luca ${ }^{1,4}$, Alessia Longoni ${ }^{1,4}$, Giuseppe Criscenti $^{1,2}$, Carlos Mota $^{3}$, Clemens van Blitterswijk $^{1,3}$ and \\ Lorenzo Moroni ${ }^{1,3,5}$ \\ 1 University of Twente, Tissue Regeneration Department, Drienerlolaan 5,7522 NB, Enschede, The Netherlands \\ 2 Research center 'E. Piaggio', Faculty of Engineering, University of Pisa, Largo L. Lazzarino 2, 56100, Pisa, Italy \\ 3 Maastricht University, MERLN Institute for Technology Inspired Regenerative Medicine, Complex Tissue Regeneration department, \\ Universiteitsingel 40, 6229 ER Maastricht, The Netherlands \\ 4 Authors contributed equally to this work. \\ 5 Author to whom any correspondence should be addressed. \\ E-mail:1.moroni@maastrichtuniversity.nl
}

Keywords: scaffolds, gradients, bone, stem cells, regenerative medicine, additive manufacturing

\begin{abstract}
Guiding bone regeneration poses still unmet challenges due to several drawbacks of current standard treatments in the clinics. A possible solution may rely on the use of three-dimensional scaffolds with optimized structural properties in combination with human mesenchymal stem cells (hMSCs). Bone presents a radial gradient structure from the outside, where the cortical bone is more compact (porosity ranging from $5 \%$ to $10 \%$ ), toward the inner part, where the cancellous bone is more porous (porosity ranging from 50\% to 90\%). Here, we present a new scaffold design with a built-in gradient in porosity, which approximate the radial bone structure. The pores of the outer ring were $500 \mu \mathrm{m}$, the ones in the middle zone were $750 \mu \mathrm{m}$ and the inner part presented pores of $1000 \mu \mathrm{m}$. The porosity of each scaffold region resembled the gradient present in bone, with the outer ring having a porosity of $29.6 \% \pm 5 \%$, the middle and inner regions a porosity of $50.8 \% \pm 8.1 \%$ and $77.6 \% \pm 3.2 \%$ respectively. hMSCs behavior was analyzed in terms of growth, extracellular matrix deposition and differentiation toward the osteogenic lineage. A trend was displayed by the hMSCs residing in different zones of the gradient scaffolds after 7, 14 and 28 days of culture in mineralization medium. Osteogenic differentiation was influenced by pore size and location in scaffolds displaying a radial porosity gradient. Cell differentiation was confirmed by gene expression with upregulation of Runx 2 and bone sialoprotein markers. Mineralization staining further confirmed the maturation of cell differentiation, as indicated by the presence of calcium and phosphate mineral deposits.
\end{abstract}

\section{Introduction}

Bone is the second most common transplanted tissue in the clinics. Bone is also one of the few tissues in our body with the highest capacity to regenerate after an injury. Yet, for severe critical sized defects, such regenerative capacity is impaired. Hence, bone regeneration is still a key field among regenerative medicine applications. The golden standard for bone replacement relies on autografts and allografts, the use of biological material harvested mainly from the iliac crest of the patient or from a deceased donor [1]. Among their advantages, the former possess desirable properties such as osteoinductivity and osteoconductivity [2], which are needed in order to promote bone repair. The latter present a lower percentage of graft incorporation and lower osteogenic properties. Beside their common use, these biological substitutes present several drawbacks such as donor-site morbidity (autograft), limited tissue availability and surgery complications [3]. Furthermore, allografts present the additional problem of risk of immune rejection and of pathogen transmission from donor to host [4]. In order to overcome these problems, a considerable effort has been done for developing convenient alternatives that will promote the regenerative ability of the host body [5]. Among these, the use of 3D scaffolds able of guiding and supporting cell activity has gained a lot of interest.

Several techniques such as gas foaming [6, 7], freeze drying [8], solvent casting and salt leaching have 
been used to generate scaffolds [9, 10]. Even though they are easy to implement, the resulting scaffolds lack several key properties, such as pore interconnectivity and mechanical properties, and present limitations in terms of tuning their pore network architecture. In order to overcome these limitations, in the past decade additive manufacturing (AM) emerged as alternative technique for scaffolds production. Thanks to the computer aided design and computer aided manufacturing (CAD-CAM) process, pore size and shape, fiber size and material composition can be varied during scaffold fabrication allowing, for example, the generation of gradient structures. In particular, extrusionbased AM technologies involve the use of a moving extrusion head that operates in the $X$ and $Y$ axes. The biomaterial of choice, typically a polymer, is heated above its melting temperature to reach a viscous state, and extruded from a nozzle in thin layers onto a stage. After the completion of each layer, the height of the extrusion head is increased and the next layer is plotted [11]. It has been already proved that this technique can be used to produce complex 3D scaffolds with defined porosity, pore size and interconnectivity [12].

Another important factor in tissue regeneration relies on the choice of a specific cell type. For bone regeneration already terminally differentiated cells such as osteoblasts can be used and would be the most logical choice. However, a further bone defect would be needed to obtain these cells. A valid alternative to osteoblasts is represented by mesenchymal stem cells (MSCs), also known as skeletal stem cells or bone marrow stromal cells [13]. It has been proved that these progenitor cells can differentiate into osteogenic, chondrogenic and adipogenic lineages [14] and preserve this differentiation potential after in vitro expansion [15]. Bone marrow, periosteum, adipose tissue, umbilical cord and placenta are considered possible human MSC sources [16]. Their differentiation can be driven by several environmental cues such as material physico-chemical properties (stiffness, surface energy) [17, 18], scaffold structural properties (porosity and pore shape) $[19,20]$, and the presence of soluble factors (BMPs, TGF- $\beta$ s) [21-23].

Apart from the general desirable characteristics of biocompatibility, osteoinductivity and osteoconductivity, the ideal scaffold for bone tissue regeneration should possess adequate mechanical and structural properties [24]. The scaffold should have enough mechanical strength to maintain the proper architecture withstanding the hydrostatic pressure [25]. Once implanted, the construct should theoretically also match the mechanical properties of the living bone to allow an early mobilization of the injured site [26]. Regarding the scaffold architecture, the construct should have pores within the range of $200-900 \mu \mathrm{m}$ and a fully interconnected pore network to allow cell and tissue in-growth and an efficient distribution of nutrients and oxygen [26]. However, it must be considered that an increase of the porosity coincide with a decrease of the mechanical properties [27], therefore a proper balance between these two elements is needed. Bones of the adult skeleton do not have a homogeneous structure, as they are composed by two regions that display different architectures. The outer highly dense region, known as cortical bone, has a porosity that ranges from $5 \%$ to $30 \%$ (mostly in the range $5 \%-10 \%$ ) whereas the inner region, called cancellous bone, has a porosity that ranges from $50 \%$ to $90 \%$. Due to the differences in porosity, cancellous bone has an elastic modulus and an ultimate compressive strength 10 times lower than the one of cortical bone [28].

Considering these gradient structural properties related to bone porosity and pore size, an appealing new strategy to design scaffolds for bone regeneration could rely on approaching such structure to promote regional cell differentiation. We have already shown that axial gradients in pore size and architecture can improve hMSCs differentiation toward the osteogenic or chondrogenic lineages [29]. Therefore, in the present study we hypothesized that it is unlikely that a uniform porous biomaterial can be suitable for cortical bone regeneration either. Inspired by cortical bone architecture, we fabricated for the first time hierarchical scaffolds with a new radial graded porosity in order to mimic the variation in bone density from the cortical bone to the cancellous bone. We studied whether such graded pore size and porosity has an influence on human MSCs behavior.

\section{Materials and methods}

\subsection{Scaffold design, plotting and characterization 2.1.1. Scaffold plotting}

Scaffolds were fabricated via an extrusion-based AM technology (Bioscaffolder, SysENG, Germany). Scaffolds were made of poly(ethylene oxide therephtalate)/poly(butylene therephtalate) (PEOT/PBT). $\mathrm{PEOT} / \mathrm{PBT}$ is a family of block co-polymers characterized by an aPEOTbPBTc nomenclature, where a is the molecular weight of the starting PEG block and $b$ and $c$ are the PEOT/PBT ratio. Briefly, the syringe was filled with the polymer (300PEOT55PBT45, PolyVation, The Netherlands), heated at $190{ }^{\circ} \mathrm{C}$, and extruded by applying a pressure of $5 \mathrm{bar}$, an auger screw rotation of $100 \mathrm{rpm}$ and a cartridge translation speed of 250-325 $\mathrm{mm} \mathrm{min}^{-1}$. The scaffold architecture was determined by a 0-90 layer configuration where fibers were deposited with a $90^{\circ}$ orientation steps between successive layers. The final scaffold was characterized by a cylindrical shape with a height of $3.75 \mathrm{~mm}$ and an outer diameter of $12 \mathrm{~mm}$ (the inner and middle diameter were 4 and $8 \mathrm{~mm}$, respectively). The fiber diameter and height was kept constant at $250 \mu \mathrm{m}$ and $150 \mu \mathrm{m}$. To produce the radial porosity gradient (RPG) constructs, the fiber spacing was varied from $500 \mu \mathrm{m}$ in the outer region to $750 \mu \mathrm{m}$ in the middle 
region, and to $1000 \mu \mathrm{m}$ in the inner region. Three types of scaffold were used as control. Two were fabricated with a homogeneous porosity, in particular maintaining the smallest $(500 \mu \mathrm{m})$ and the biggest $(1000 \mu \mathrm{m})$ fiber spacing of the RPG scaffolds. The third one was designed with an inverted gradient of porosity (IPG), with the biggest pore volume outside and the smallest inside.

\subsubsection{Porosity evaluation}

The porosity of the RPG and control scaffolds was evaluated following Landers et al theoretical approach [30]:

$$
P=1-\frac{V \text { scaffold }}{V \text { cube }}=1-\frac{\pi}{4} * \frac{d_{1}^{2}}{d_{2} * d_{3}} .
$$

Where, $P$ is the scaffold porosity, while $d_{1}$ is the fiber diameter, $d_{2}$ is the fiber spacing, and $d_{3}$ is the layer thickness of each scaffold.

\subsubsection{Mechanical characterization}

The mechanical properties of RPG scaffolds and relative controls in wet and dry conditions were evaluated through uniaxial compression tests. For each configuration, 4 samples were analyzed. The length-to-diameter $(L / d)$ aspect ratio $(1 / 3)$ provided a uniform compression stress in the region where the strain was measured. This value is the best compromise for cylindrical samples to avoid spurious bending or buckling (if $L / d \gg 1 / 3$ ) or a state of not uniaxial compression (if $L / d \ll 1 / 3$ ). In our case, $L /$ $d \approx 0.319 \approx 1 / 3$ for the fabricated scaffolds. Samples were positioned in a standard compression block and aligned to the $500 \mathrm{~N}$ load cell of a Zwick testing machine. To evaluate the influence of an aqueous environment and possible perfusion effects, tests were performed under two different environmental conditions: in a nitrogen atmosphere (dry condition) and in culture medium (alpha-MEM) at $37^{\circ} \mathrm{C}$ (wet condition). In the second case, the samples were left overnight in the medium at $37^{\circ} \mathrm{C}$. All the specimens were preloaded with $0.1 \mathrm{~N}$ and preconditioned by a series of ten cycles until reaching a strain of $5 \%$ with a strain rate of $1 \mathrm{~mm} \mathrm{~min}^{-1}$ to reduce the hysteresis. Subsequently, the scaffolds were compressed at $1 \mathrm{~mm} \mathrm{~min}{ }^{-1}$ until failure. From the stress-strain curve, the elastic region and the Young's modulus $(E)$ were evaluated.

\subsection{Cell seeding and culture}

\subsubsection{Cell expansion and culture conditions}

Pre-selected hMSCs (male, age 22) were purchased from Prockop laboratories (Temple, Texas). Cells at passage 2 were expanded at initial seeding density of about 1000 cells $\mathrm{cm}^{-2}$ in proliferation medium at approximately $80 \%$ confluency prior the seeding on $3 \mathrm{D}$ scaffolds. Cells were grown at $37^{\circ} \mathrm{C}$ in a humidified atmosphere with $5 \% \mathrm{CO}_{2}$. Basic medium (BM) was used after cell seeding on the scaffolds as control for mineralization medium (MM). BM consisted of alpha minimum essential medium (MEM- $\alpha$, Gibco) supplemented with $10 \%$ fetal bovine serum (FBS, Lonza), L-glutamine (2 mM, Gibco), penicillin (100 $\mathrm{U} \mathrm{ml}^{-1}$, Gibco) and streptomycin (100 $\mu \mathrm{g} \mathrm{ml}^{-1}$, Gibco), and ascorbic acid (0.2 mM, Sigma). MM, used for cell differentiation toward the osteogenic lineage, consisted of BM containing $10 \mathrm{nM}$ dexamethasone (Sigma) and $0.01 \mathrm{M} \quad \beta$-glycerophosphate (BGP, Sigma). During cell expansion, proliferation medium, which consisted of BM supplemented with basic fibroblast growth factor (1 ng ml$l^{-1}, \mathrm{bFGF}$, Instruchemie) was used.

\subsubsection{Cell seeding and culture on FDM-scaffolds}

The scaffolds were sterilized in $70 \%$ ethanol for $45 \mathrm{~min}$, subsequently washed twice in PBS for $5 \mathrm{~min}$ and finally incubated in BM overnight to pre-wet them and promote protein adsorption. Before seeding, scaffolds were dried and placed in a non-treated 24well plate (NUNC). Harvested P3 hMCs were seeded on scaffolds with a density of 500000 cells in $100 \mu \mathrm{l}$ of BM. To obtain a homogeneous distribution in static conditions, the scaffolds were ideally divided into 4 quadrants and the initial seeding volume was split into 4 drops of $25 \mu \mathrm{l}$ (125000 cells/drop), one for each quadrant. After $4 \mathrm{~h}$ of incubation in which cells were allowed to adhere, the medium was filled up to $1.5 \mathrm{ml}$. The next day, medium was changed to the experimental culture conditions (BM and MM). The media were refreshed every $2-3 \mathrm{~d}$ and every time the scaffolds were rotated of $180^{\circ}$ in order to reduce the effect of the gravity force. Cells were grown at $37^{\circ} \mathrm{C}$ in a humidified atmosphere with $5 \% \mathrm{CO}_{2}$.

\subsection{Biochemical analysis}

All the biochemical studies were performed after 7, 14 and $28 \mathrm{~d}$ of culture in MM and BM. DNA and ALP assays were performed in a 'partition' manner: the three different areas of the scaffolds (outer, middle and inner part) were divided using a cutter and analyzed separately in order to have a better understanding of how cellular behavior is affected by each porosity. Triplicates were used for each condition at each time point.

\subsubsection{DNA assay}

Cell number per area was obtained from the $\mu \mathrm{g}$ of DNA, calculated with CyQuant DNA assay kit (Molecular Probes, Invitrogen) according to the manufacturer's description. Briefly, after the separation of the three areas of the scaffolds, they were further cut in order to improve the lysis efficiency. Samples were stored at $-20{ }^{\circ} \mathrm{C}$ and freeze-thawed 5 times. Afterwards, cells within the scaffolds were lysated using the same cell lysis buffer used for the ALP activity assay. After $1 \mathrm{~h}$ of incubation at room temperature, the samples were sonicated (Branson Sonifier) twice for 
Table 1. List of primers used for gene expression analysis in RPG and control scaffolds.

\begin{tabular}{lll}
\hline Gene & Forward primer & Reverse primer \\
\hline B2M & ACAAAGTCACATGGTTCACA & GACTTGTCTTTCAGCAAGGA \\
Runx2 & TGGTTACTGTCATGGCGGGTA & TCTCAGATCGTTGAACCTTGCTA \\
BSP & CCCCACCTTTTGGGAAAACCA & TCCCCGTTCTCACTTTCATAGAT \\
\hline
\end{tabular}

$15 \mathrm{~s}$. To avoid the interference caused by the binding of the dye to the RNA, $100 \mu$ l of the samples were incubated for $1 \mathrm{~h}$ at room temperature with $100 \mu \mathrm{l}$ of lysis buffer provided by the kit (Component $\mathrm{B}$ diluted in $180 \mathrm{mM} \mathrm{NaCl}, 1 \mathrm{mM}$ EDTA in distilled water in the ratio 1:20) in which RNAse was diluted 1000 times. Quantification of the total DNA was performed using a green fluorescent dye provided by the kit (excitation $480 \mathrm{~nm}$, emission $520 \mathrm{~nm}$ ). Fluorescence was measured at $480 \mathrm{~nm}$ using a spectrophotometer LS50B (Victor 3, Perkin Elmer) and DNA concentrations were calculated from a $\lambda$ DNA standard curve. Cell density in each area of the gradient scaffolds was calculated by measuring the DNA content of each area, which was normalized by the pore volume of total amount of pores in that area of the scaffold.

\subsubsection{ALP activity assay}

Constructs were incubated for $1 \mathrm{~h}$ at room temperature in a cell lysis buffer composed of $0.1 \mathrm{M} \mathrm{KH}_{2} \mathrm{PO}_{4}$ and $0.1 \%$ Triton X-100 (Acros Chemicals), at pH 7.8. ALP activity quantification was performed using a CDP-Star kit (Roche), according to the manufacturer's protocol. Briefly, $40 \mu \mathrm{l}$ of CDP-Star reagent were added to $10 \mu \mathrm{l}$ of cell lysate. After $15 \mathrm{~min}$ of incubation at room temperature in the dark, ALP activity was measured with a spectrophotometer LS50B (Victor 3, Perkin Elmer). The obtained values were normalized to the DNA amount per area and to the single pore volume in order to take into account also the structural differences between the areas. Average conditions were represented as a relative value as all the results were compared to the ALP activity found in the inner part of the radial scaffold cultured in BM for $7 \mathrm{~d}$.

\subsection{Gene expression analysis}

Gene expression studies were performed after 7, 14 and $28 \mathrm{~d}$ of culture in MM and BM. Also in this case the analyses were performed in a partition manner, dividing the three areas with different porosity. Quadruplicates were used for each condition at each time point.

\subsubsection{RNA isolation and cDNA synthesis}

In order to analyze the expression of osteogenic markers, samples were cut and transferred to $2 \mathrm{ml}$ eppendorf tubes. Before storing at $-80{ }^{\circ} \mathrm{C}, 750 \mu \mathrm{l}$ of TRIzol $^{\circledR}$ (Invitrogen) were added. In order to isolate the RNA, $150 \mu$ l of chloroform were added to all the samples and mixed by vigorously shaking the tubes. The obtained mixture was centrifuged at $12000 \mathrm{~g}$ for $20 \mathrm{~min}$ at $4{ }^{\circ} \mathrm{C}$. The aqueous clear phase containing the RNA was transferred into a new eppendorf tube and mixed with an equal quantity of $70 \%$ ethanol. The product was transferred to the filter columns taken from ISOLATE II RNA mini kit (Bioline) for RNA isolation and the following steps were performed according to the manufacturer's protocol. RNA was eluted in $40 \mu \mathrm{l}$ of RNAse-free water and its concentration and purity was determined using an ND1000 spectrophotometer. For cDNA synthesis, iScript ${ }^{\mathrm{TM}}$ (Bio-Rad) was used according to manufacturer's protocol.

\subsubsection{Quantitative polymerase chain reaction ( $q P C R$ )}

The obtained cDNA was used to perform qPCR with an iQ SYBR ${ }^{\boxplus}$ Green Supermix (Bio-Rad). Primers are listed in table 1. PCR reactions were performed using CFX Connect $^{\mathrm{TM}}$ Real-Time System (Bio-Rad) under the following conditions: cDNA was denaturated for $10 \mathrm{~min}$ at $95^{\circ} \mathrm{C}$, followed by 40 cycles consisting of $15 \mathrm{~s}$ at $95^{\circ} \mathrm{C}$, $15 \mathrm{~s}$ at $60^{\circ} \mathrm{C}$ and $15 \mathrm{~s}$ at $72^{\circ} \mathrm{C}$. A melting curve was generated for each reaction in order to test primer dimer formation and non-specific amplification. The cycle threshold (CT) values were determined using the Bio-Rad iQ5 optical system software, in which a threshold value was set for the fluorescent signal in the lower log-linear part above the baseline. The obtained CT values were normalized to the ones of the housekeeping gene (B2M) and to the $\triangle \mathrm{CT}$, which is the subtraction of the CTvalue from the average of the CT of the control condition. The results were expressed as the relative mRNA expression calculated as $2-\Delta \mathrm{CT}$, and successively normalized to the gene expression level determined in the inner part of the radial scaffold after $7 \mathrm{~d}$ of cell culture in BM.

\subsection{Imaging}

2.5.1. Scanning electron microscopy (SEM) and energydispersive $x$-ray spectroscopy (EDX) analysis

Cell attachment and distribution after $24 \mathrm{~h}, 7,14$ and 28 d were observed using a Philips XL ESEM-FEG. Scaffolds were rinsed twice with PBS and fixed in 10\% formalin for $30 \mathrm{~min}$. Subsequently, the samples were cut in progressive sections and dehydrated in sequential ethanol series $(50 \%, 60 \%, 70 \%, 80 \%, 90 \%, 96 \%$ and $100 \%), 30 \mathrm{~min}$ for each concentration. For the final dehydration step, scaffolds were immersed in hexamethyldisilazane (Sigma-Aldrich) and the solvent was left to evaporate overnight. Finally samples were gold sputtered (Cressington) prior to SEM analysis. SEM images were obtained under high vacuum with an acceleration voltage of $10 \mathrm{kV}$ and a working distance of $25 \mathrm{~mm}$. An EDX (Ametek, USA) system integrated to the SEM was used in order analyze the possible co-localization of calcium (Ca) and phosphate 
$(\mathrm{P})$ in the extracellular matrix. The spectra were taken under high vacuum with an acceleration voltage of $10 \mathrm{kV}$ and a working distance of $10 \mathrm{~mm}$.

\subsubsection{Alizarin red S staining}

Calcium mineralization was qualitatively determined by alizarin red S staining after $28 \mathrm{~d}$ of culture. Samples were fixed in $10 \%$ formalin for $30 \mathrm{~min}$ and washed twice with distilled water. Subsequently, scaffolds were cut in progressive sections in order to analyze calcium deposition also in the inner part. Each section was stained with alizarin red $\mathrm{S}$ for $2 \mathrm{~min}$ and washed several times with distilled water. Pictures were taken using a stereomicroscope (Nikon SMZ800 with Q-imaging Retiga 1300 camera).

\subsection{Statistical analysis}

A one-way statistical analysis of variance followed by a Tukey's post hoc test was used with a significant level $p$ of 0.05 to determine differences between the groups. To evaluate the differences between BM and MM, a two-tailed Student's t-test was performed. The confidence level was set to 0.05 . Values in this study are reported as mean and standard deviation.

\section{Results}

\subsection{Scaffold characterization}

\subsubsection{Real porosity evaluation}

SEM images were used in order to measure the real values of fiber diameter $(d 1)$, fiber spacing $(d 2)$ and layer thickness ( $d 3$ ) (figure 1 ). The values of $\mathrm{d} 1$ and $\mathrm{d} 3$ were theoretically kept constant in the different areas and their values were set to $250 \mu \mathrm{m}$ and $150 \mu \mathrm{m}$, respectively. The layer thickness revealed consistency between the theoretical and the real values. Moreover, it was constant in the different areas of the scaffold as $d 3$ real values were $153 \mu \mathrm{m} \pm 12 \mu \mathrm{m}, 157 \mu \mathrm{m} \pm 10 \mu \mathrm{m}$ and $154 \mu \mathrm{m} \pm 12 \mu \mathrm{m}$ in the internal, middle and external areas, respectively.

Higher differences were observed in the fiber diameter, as $d 1$ was $202 \mu \mathrm{m} \pm 15 \mu \mathrm{m}$ in the internal part, $282 \mu \mathrm{m} \pm 29 \mu \mathrm{m}$ in the middle part and $261 \mu \mathrm{m} \pm 43 \mu \mathrm{m}$ in the external one. Fiber spacing was the only parameter that changed in order to have different pore volumes in the three areas of the RPG scaffolds. The obtained values were consistent with the theoretical ones, as $d 2$ was $475 \mu \mathrm{m} \pm 4 \mu \mathrm{m}$ in the external part, $750 \mu \mathrm{m} \pm 26 \mu \mathrm{m}$ in the middle part and $939 \mu \mathrm{m} \pm 20 \mu \mathrm{m}$ in the internal one. The real porosities of each region are listed in table 2.

\subsubsection{Mechanical characterization}

The mechanical properties of RPG and control scaffolds were tested in order to evaluate the influence of the different porosities. In order to take into account the structural differences between the scaffolds, the same cross-sectional area (CSA) was considered for each type of scaffold. In particular, the CSA was defined as the total surface of the scaffold considered as a bulk structure. The stress was then defined as the ratio between the applied force and the CSA. Therefore, the use of the same CSA implied a different stress value and finally a different Young's modulus, which was related to the real structure of the scaffold. Comparing the Young's modulus in dry conditions, the control with the smallest porosity showed a significantly higher value compared to the RPG and the IPG scaffolds (figure 2, tables 3 and 4). In wet conditions, no differences were observed among the samples, apart from the control with the bigger pore volume and the IPG scaffolds. Considering the RPG scaffolds, no differences were found between dry and wet conditions. When comparing the Young's modulus of RPG scaffold with the controls with homogenous pore volume, a lower value was measured in dry conditions, whereas RPG scaffolds had a higher modulus similar to the homogeneous controls in wet conditions.

\subsection{Cell seeding efficiency and distribution}

Cell seeding efficiency (CSE) was evaluated after $24 \mathrm{~h}$ (figure 3). CSE values ranged from $23.6 \% \pm 4.8$ to $35.8 \% \pm 7.3 \%$ and no statistically significant differences were found among the controls and the RPG scaffolds. Once it was proved that both in controls and RPG scaffolds there was approximately the same initial amount of cells, the effect of the pore size architecture on cell distribution inside the RPG scaffolds was evaluated. The DNA quantification showed that there were no statistically significant differences among inner, middle and outer region. This result further confirmed that the differences in pore size and porosity did not affect cell distribution. The cells seemed to be homogeneously distributed inside the samples. In order to evaluate cell morphology and distribution, both controls and RPG scaffolds were cut in 3 progressive sections and each one was analyzed using SEM. The adhered cells appeared well spread on the fibers and homogeneously distributed (figure 3(C)). hMSCs seeded in the area with the lowest porosity already started to create bridges between the fibers. No cell clusters due to the cell seeding were observed. This could be due to the high surface available compared to the number of seeded cells.

\subsection{Effect of porosity and pore size on hMSC differentiation}

\subsubsection{Evaluation of ALP activity}

ALP activity was evaluated after 7, 14 and 28 days (figure 4). When considering only normalization with respect to cell content, a statistically higher ALP activity was measured in MM compared to BM only after 28 days. A general trend showing a higher ALP/ DNA ratio in the external region of the scaffolds was measured at all time points. Such trend was statistically 

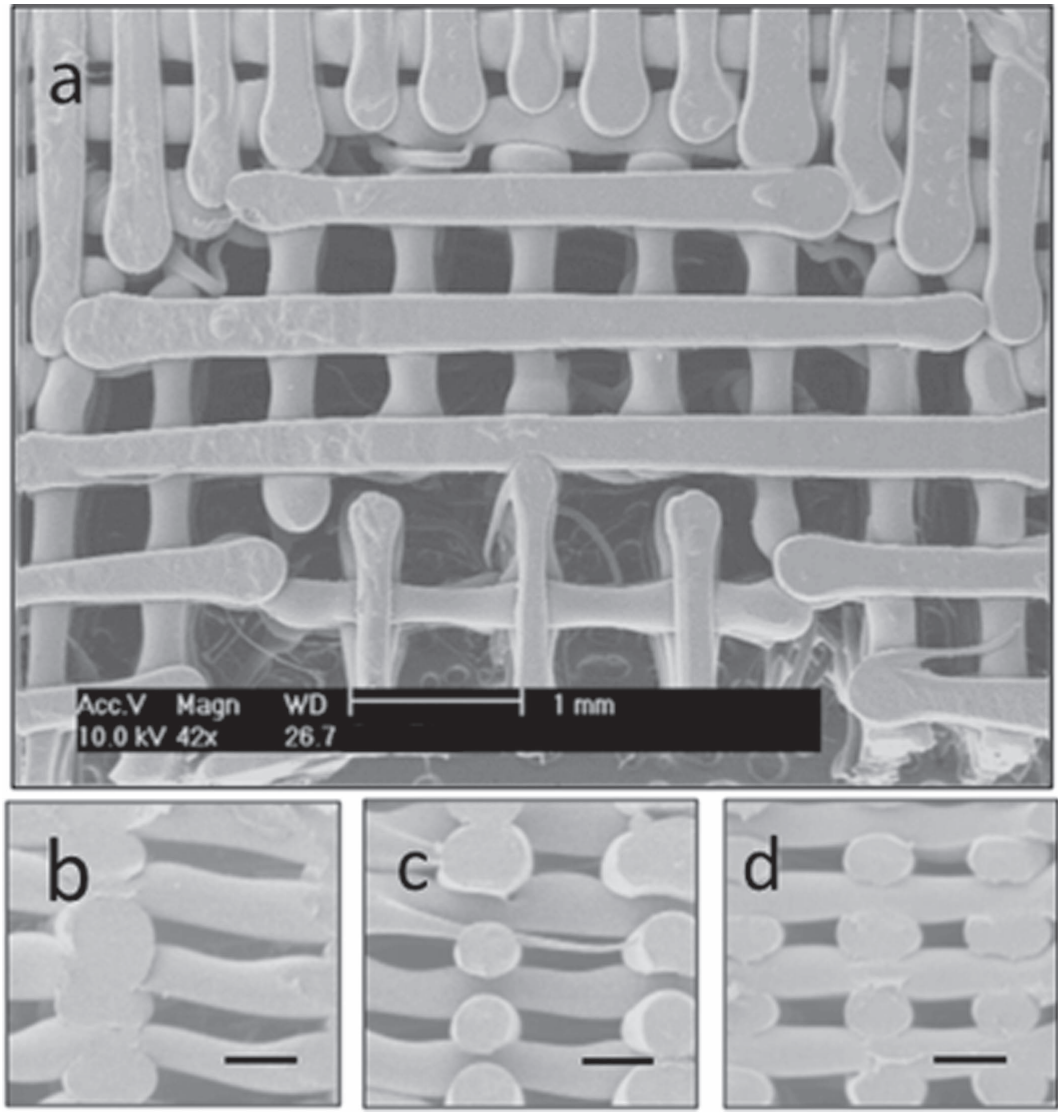

Figure 1. SEM micrograph showing the different areas of the RPG scaffolds. (a) represents a top view whereas (b)-(d) represent side views of the different areas of the RPG scaffolds, namely the inner (b), the middle (c), and the outer (d) ones respectively. Scale bars: (a) $1 \mathrm{~mm}$; (b)-(d) $200 \mu \mathrm{m}$.

Table 2. Table displaying the experimentally evaluated structural parameters of the RPG scaffolds.

\begin{tabular}{lccc}
\hline & Inner region & Middle region & Outer region \\
\hline Theoretical porosity $(\%)$ & 68 & 56 & 35 \\
Experimental porosity $(\%)$ & $77.6 \pm 3.2$ & $50.8 \pm 8.1$ & $29.6 \pm 5.0$ \\
Pore volume $\left(\mathrm{mm}^{3}\right)$ & $7 \times 10^{-2} \pm 1.8 \times 10^{-2}$ & $2.2 \times 10^{-2} \pm 7.1 \times 10^{-3}$ & $5.9 \times 10^{-3} \pm 1.7 \times 10^{-3}$ \\
$d_{1}(\mu \mathrm{m})$ & $201.8 \pm 14.6$ & $282 \pm 29.1$ & $261 \pm 43$ \\
$d_{2}(\mu \mathrm{m})$ & $938.6 \pm 20.4$ & $750.2 \pm 26.5$ & $474.4 \pm 4.4$ \\
$d_{3}(\mu \mathrm{m})$ & $153.4 \pm 11.7$ & $157.2 \pm 9.8$ & $154.8 \pm 11.6$ \\
\hline
\end{tabular}

significant in MM at day 14 in the 500 control scaffolds and at day 28 in 1000 control scaffolds as well as in IPG and RPG.

Cell density in each area of the RPG and the control scaffolds was calculated at each time point. Higher densities were observed in the internal part of IPG scaffolds. Similarly, higher densities were found in the external region of RPG scaffolds, though at lower levels than IPG internal regions. No differences were observed between the densities of the two control scaffolds with a homogeneous porosity after 7 and 14 days. After 28 days of culture cell densities in the different areas of the control with the smallest pore size became significantly higher compared to the ones of the control with the biggest pore size (figure 5). However, no variations were observed between the different areas within the same scaffold. In order to have a visual confirmation of the data obtained for the cell density, the samples were cut in progressive sections and analyzed with SEM. Figure 5 shows representative pictures for each pore size and time point. The images confirmed that the pore closure process started earlier and proceeded faster in the scaffold with the smallest porosity.

When considering also the different pore volume in the IPG and RPG scaffolds, however, a significantly higher ALP activity was observed in the external region of the IPG scaffolds, corresponding to the largest pore size, at all time points (figure 6). A similar trend was observed for RPG scaffolds for the internal region, again corresponding to the largest pore size, though not statistically significant compared to the other regions. 


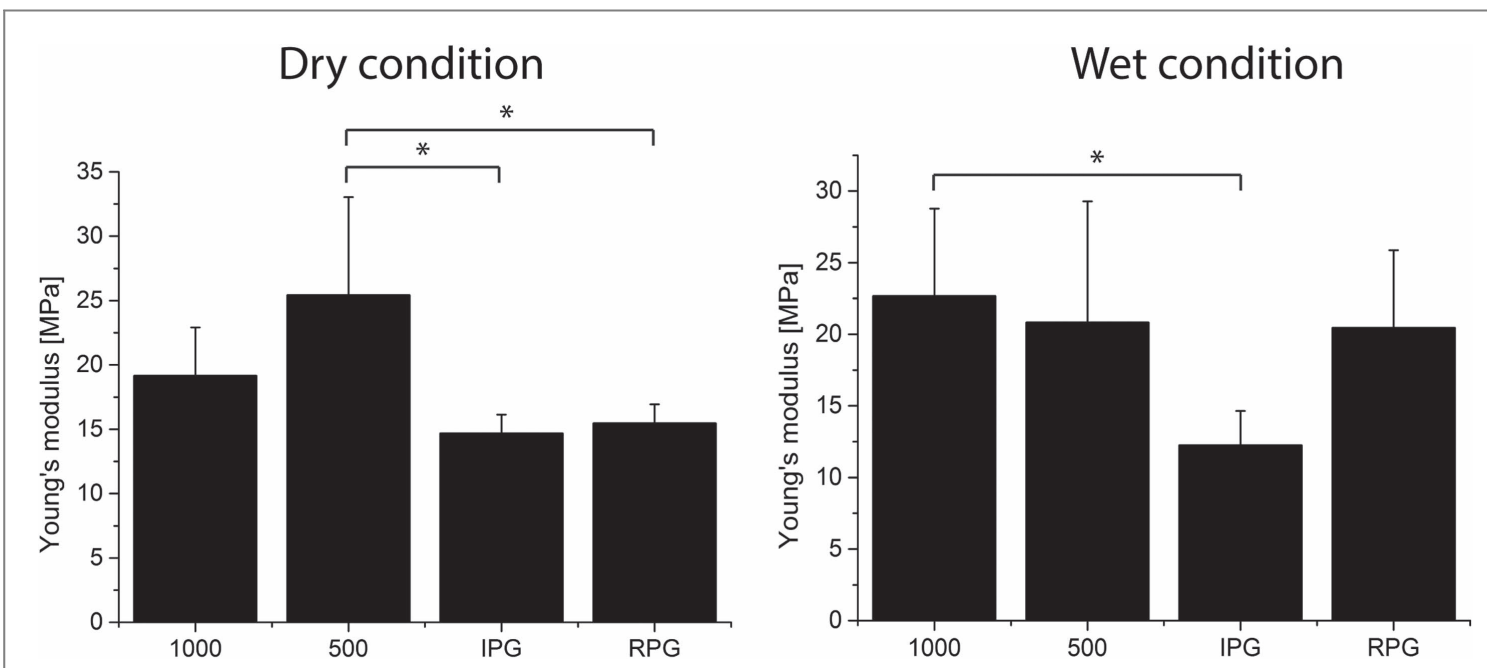

Figure 2. Young's modulus was evaluated both in dry and wet conditions in order to simulate the culture conditions for the RPG and the controls. In dry conditions, the 500 control scaffold showed the highest Young's modulus, whereas these differences decreased in wet conditions. * ndicates statistical significance $(P<0.05)$. RPG means radial porosity gradient; IPG means inverted radial porosity gradient; 500 and 1000 refer to scaffolds with homogenous pore size, where a fiber spacing of $500 \mu \mathrm{m}$ produced scaffolds with the smallest pore size and a fiber spacing of $1000 \mu \mathrm{m}$ produced scaffolds with the largest pore size analyzed in the RPG and IPG scaffolds.

Table 3. Young's modulus of the gradient and control scaffolds under dry conditions along with the linearity range.

\begin{tabular}{lcc}
\hline Dry conditions & Young's modulus (MPa) & Linearity range \\
\hline 1000 & $19.17 \pm 3.73$ & $16-26$ \\
500 & $25.43 \pm 7.6$ & $19-27$ \\
IPG & $14.68 \pm 1.46$ & $18-26$ \\
RPG & $15.47 \pm 1.46$ & $11-18$ \\
\hline
\end{tabular}

Table 4. Young's modulus of the gradient and control scaffolds under wet conditions along with the linearity range.

\begin{tabular}{lcc}
\hline Wet conditions & Young's modulus $(\mathrm{MPa})$ & Linearity range \\
\hline 1000 & $22.68 \pm 6.09$ & $16-26$ \\
500 & $20.83 \pm 8.46$ & $18-30$ \\
IPG & $12.26 \pm 2.39$ & $14-22$ \\
RPG & $20.46 \pm 5.41$ & $18-25$ \\
\hline
\end{tabular}

\subsubsection{Gene expression analysis}

Gene expression of BSP and Runx 2 was evaluated after 7, 14 and 28 days of culture for RPG and IPG scaffolds. All values were normalized against the expression obtained after 7 days of culture in BM in the inner part of RPG scaffolds in order to compare the upregulation of the two genes in the different areas throughout the culture period (figure 7). Generally, osteogenic gene expression was more upregulated in the external region of RPG and IPG scaffolds. After 14 and 28 days a higher expression of Runx 2 was observed in the outer region of the RPG scaffolds characterized by smaller pore size. Consistently with Runx 2 upregutation, also BSP showed an upregulation after 14 and 28 days with higher fold change in the outer region of the RPG scaffolds. In IPG scaffolds, Runx2 expression was higher in the inner part characterized by lower pore size after 14 days of culture. At day 28, however, its expression became significantly higher in the outer region characterized by larger pore size. This increase corresponded to a significant increase of BSP expression in the outer region.

\subsubsection{Alizarin red S staining and qualitative observation of calcium deposition}

An Alizarin Red S staining after 28 days of culture was employed in order to determine the presence of calcium minerals in the scaffold and analyze matrix mineralization. Despite at a first glance it was hard to observe differences between the scaffolds cultured in $\mathrm{BM}$ and $\mathrm{MM}$, at higher magnification it was possible to identify calcium deposition only on the fibers of scaffolds cultured in MM (figure 8). No main differences were observed among the different areas of RPG scaffolds. To confirm the presence of mineralization nodules, a point analysis with the EDX was performed on the sample cultured in MM, revealing the presence of both calcium and phosphate.

\section{Discussion}

A scaffold with a radial gradient structure was designed, plotted and analyzed for its capacity to guide the differentiation of hMSCs in presence and absence of osteogenic soluble factors. The experimental values of the structural parameters characterizing RPG scaffolds were similar to the designed ones and within the range of natural bone. Cortical bone has a porosity that ranges from $5 \%$ to $30 \%$ (mostly in the range of $5 \%$ $10 \%$ ) whereas cancellous bone displays a porosity that ranges from $50 \%$ to $90 \%$ [28]. Consistently with this data, porosities of $77.6 \% \pm 3.2 \%, 50.8 \% \pm 8.1 \%$ and $29.6 \% \pm 5 \%$ were displayed by the outer, middle and inner region, respectively. For the inner region, the experimental porosity was higher compared to the 


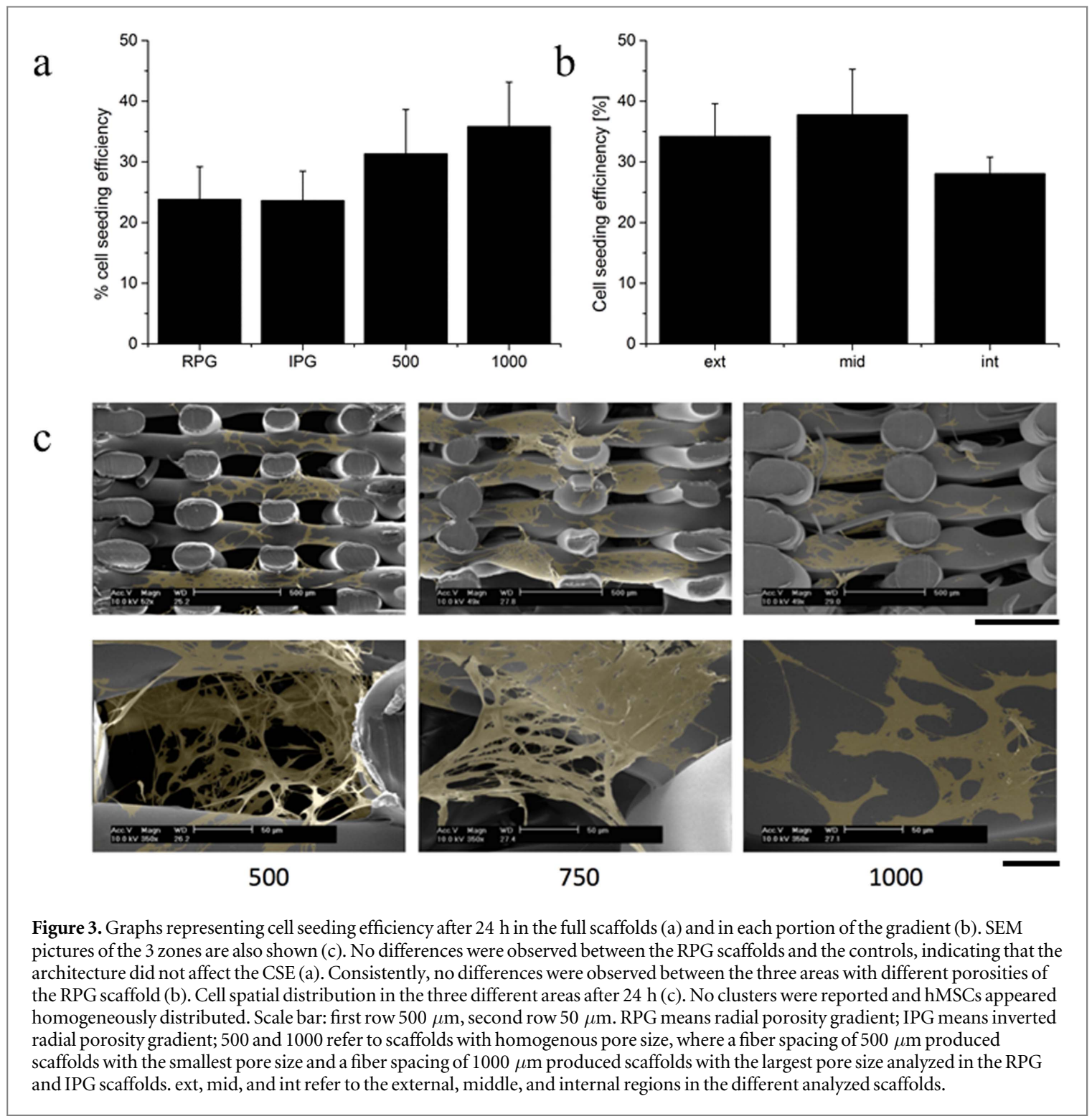

expected one, whereas it was smaller for the middle and outer region. This difference was mainly due to the variation in fiber diameter $\left(d_{1}\right)$, which was higher than expected in the middle and external areas whereas it was smaller in the internal one. The possibility to tailor structural properties like pore size, porosity and pore distribution within the same scaffold have always appeared as an appealing tool for fundamental studies on the interactions between cells and such structural parameters as well as for more practical tissue regeneration applications. The use of gradient structures, for example, could facilitate the implant capability of withstanding different mechanical loads at specific regions minimizing stress-shielding [31]. Several materials and different techniques have been used in order to obtain a controlled structural gradient. Oh et al, for example, fabricated a gradient scaffold with a range of porosities from $80 \%$ to $94 \%$ exploiting the centrifugation of a cylindrical mould containing fibrillike polycaprolactone (PCL) followed by fibril bonding by heat treatment to study the interactions between different cell types and pore size [32]. Similarly to this work, Tampieri et al tried to fabricate porous hydroxyapatite (HA) bodies in order to mimic bone tissue morphology varying the characteristics of starting HA powders and the impregnation strategy of cellulosic sponges with rheologically optimized slurries [33]. Despite the remarkable results obtained in these studies highlighting the advantages of using gradients in scaffold design, there are only few examples in literature of their actual applications. This could be due to long and complex manufacturing procedures and to the lack of complete control over the scaffold internal architecture of the biofabrication approaches so far developed. The novelty of this study is the design and fabrication of a radial porosity graded structure exploiting AM technology. Using this technique, it was possible to overcome the above mentioned drawbacks, as the plotting procedure consisted in a less complex one-step method which allowed an excellent control over pore size, shape, orientation, and interconnection [31]. Despite this technique has already been used to 


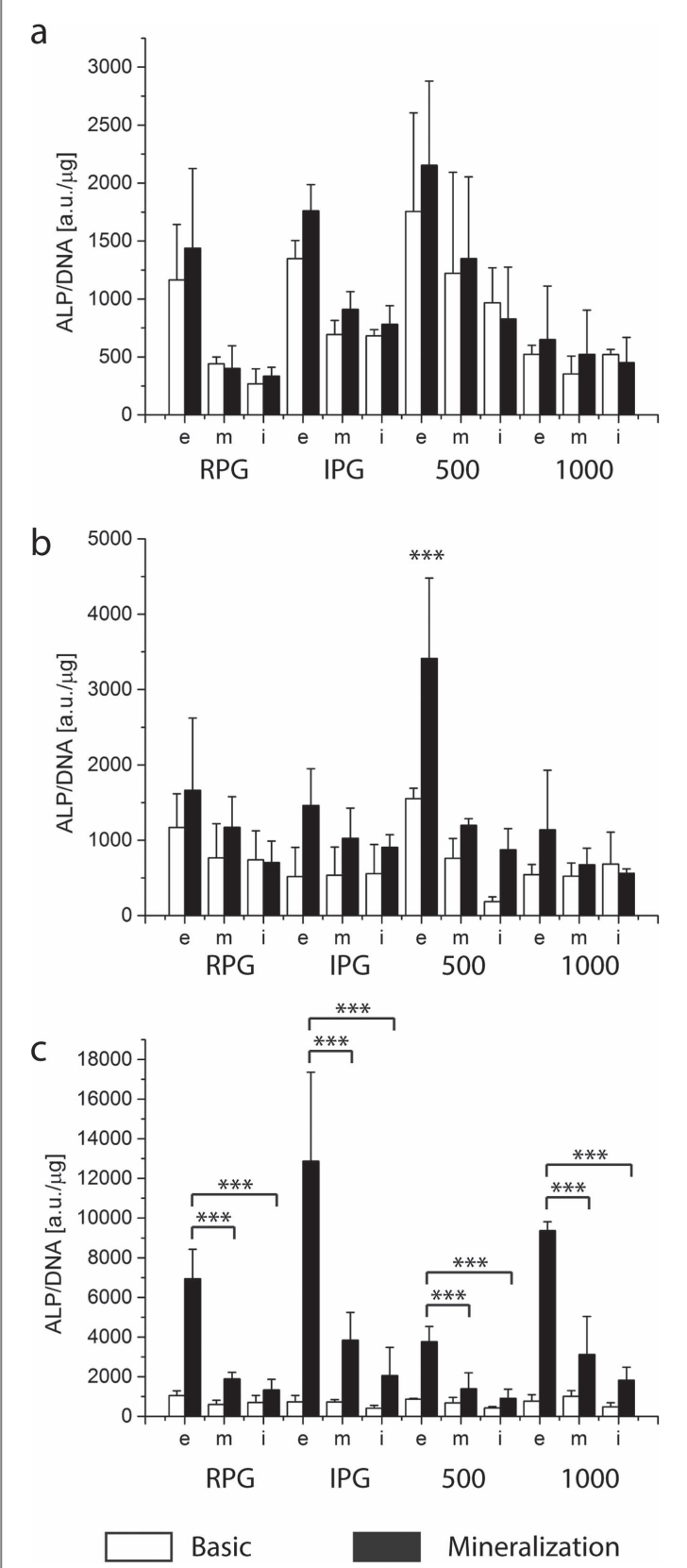

Figure 4. Plots displaying the ALP activity normalized by DNA at $7 \mathrm{~d}$ (a), $14 \mathrm{~d}$ (b) and $28 \mathrm{~d}$ (c), in the different zones of the non-gradient, IPG and RPG scaffolds. ${ }^{* * *}$ statistical significance versus other zones within the same scaffold and under the same conditions, $p<0.001$. In (b), IPGe scaffolds cultured in basic medium showed statistical significance toward all the other conditions and scaffold zones with exception to IPGe scaffolds in mineralization medium. RPG means radial porosity gradient; IPG means inverted radial porosity gradient; 500 and 1000 refer to scaffolds with homogenous pore size, where a fiber spacing of $500 \mu \mathrm{m}$ produced scaffolds with the smallest pore size and a fiber spacing of $1000 \mu \mathrm{m}$ produced scaffolds with the largest pore size analyzed in the RPG and IPG scaffolds. e, $\mathrm{m}$, and i refer to the external, middle, and internal regions in the different scaffolds analyzed.

produce gradient structures aimed at maximizing CSE [34], only another study showing the effect of pore size and porosity on chondrocyte differentiation was performed [35]. More recently, we have reported on the fabrication of axial gradient scaffolds, where pore size was changed longitudinally along the scaffolds, and showed the influence of such structural gradients on hMSCs skeletal differentiation [29, 36]. In this respect, the analysis of radial structural pore size and porosity gradients on the osteogenic differentiation capacity of hMSCs is here reported for the first time on AM scaffolds. The RPG scaffolds were characterized by a complex structure with porosity variation between regions. This implied a different CSA in the different regions, which influenced the stress distribution on the scaffold. For this reason, the same CSA was considered for each type of analyzed scaffold in order to evaluate the influence of the structural differences. RPG scaffolds displayed a similar stiffness with respect to the controls; this is probably due to structural factors such as the orientation and relative positioning of the fibers along the scaffold, which can play a role in determining the final mechanical performance [34]. RPG and IPG scaffolds showed no statistical differences, probably because of the similar total CSA.

The initial cell seeding procedure is a critical step in a tissue engineering process. CSE and cell distribution analysis were performed in order to exclude the possibility that the further obtained results could be related to a different initial experimental condition among the RPG scaffolds and the controls. In order to minimize cell loss, the seeding parameters were chosen following Leferink et al [37]. CSE values ranged from $23.6 \% \pm 4.8$ to $35.8 \% \pm 7.3 \%$, which correlated well with values in literature [38]. In contrast to recent studies, which have highlighted that in AM scaffolds the pore structure and scaffold architecture can play an important role in CSE of human osteosarcoma cells [34], no statistically significant differences were found among the controls and RPG scaffolds for hMSCs. Similar results were obtained by Leferink et al comparing the CSE of hMSCs on three types of cylindrical scaffolds characterized by the same outer dimensions but different porosities. In particular, structure with porosities of $48 \%, 65 \%$ and $90 \%$ were investigated [37].

To evaluate cell differentiation, ALP activity was used as first readout. The increase in ALP activity along the entire culture period in MM represented a first indication of hMSCs differentiation toward the osteogenic lineage. When taking into consideration only the cell amount in each region of the gradient scaffolds, the ALP activity seemed to be independent from the sequence of the pore size regions in the RPG and IPG scaffolds. ALP activity was significantly higher always in the external regions, being the large pore size region in the IPG scaffolds and the small pore size region in the RPG scaffolds, thus suggesting a stronger influence of nutrient (e.g. oxygen) availability compared to the scaffold's graded structural properties. This difference in the enzyme activity, however, could be also correlated to different cell densities in the three regions of the RPG and the IPG scaffolds, as shown in figure 5. Goldstein proved that in $2 \mathrm{D}$ the 

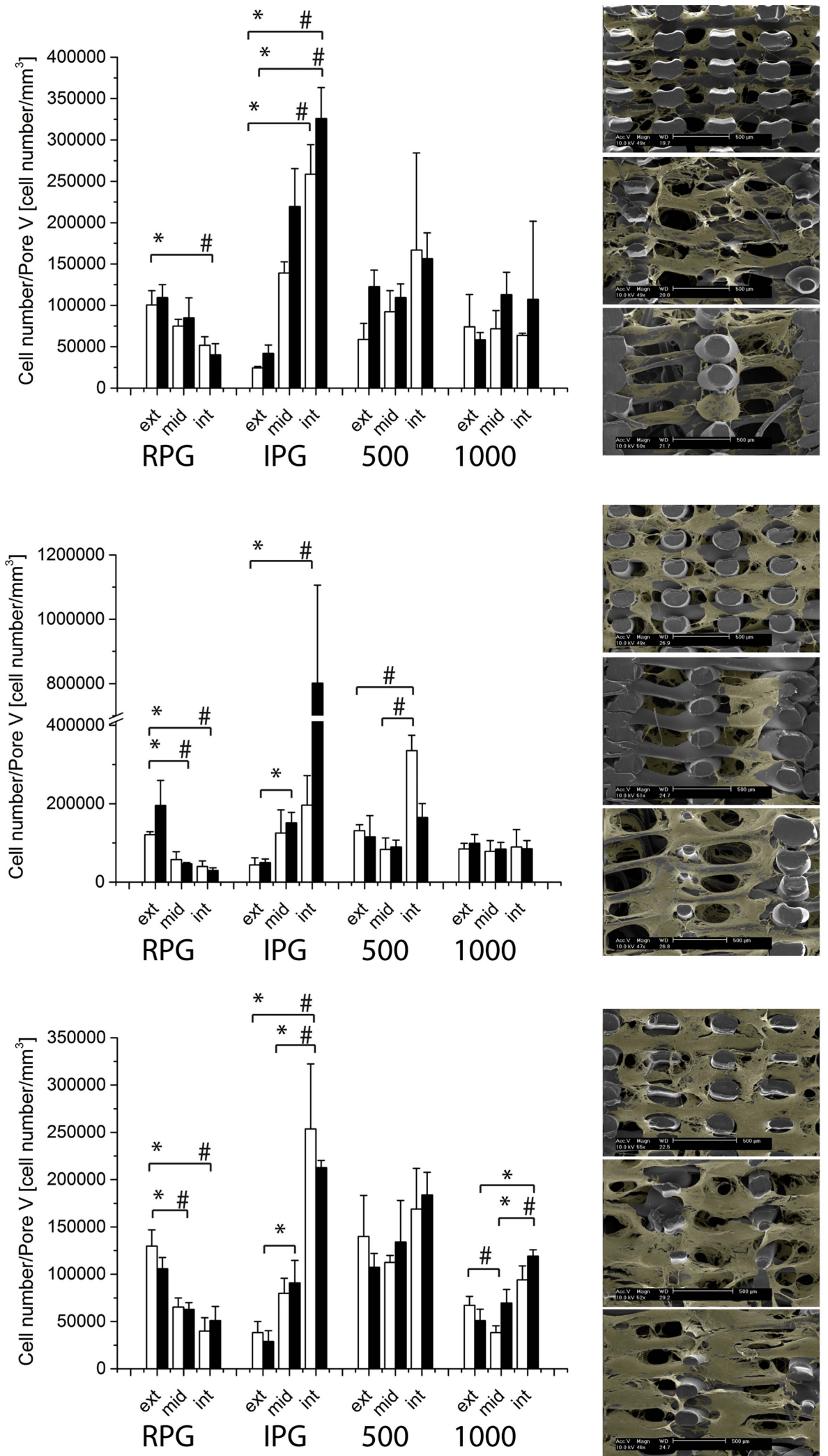

Figure 5. Cell density in the different area of control scaffolds and RPG and IPG scaffolds along time, (a) 7 days, (b) 14 days and (c) 28 days. On the right side of each plot SEM micrograph of the cells residing in small pores $(500 \mu \mathrm{m})$, medium pores $(750 \mu \mathrm{m})$ and large pores $(1000 \mu \mathrm{m})$ at different times. IPG and RPG scaffolds displayed differences in cell density from 7 days whereas in scaffolds with constant pore size the differences become significant after 14 days. * significance between mineralization conditions, \# significance between basic conditions, $p<0.05$. Scale bar in SEM micrograph $500 \mu \mathrm{m}$. RPG means radial porosity gradient; IPG means inverted radial porosity gradient; 500 and 1000 refer to scaffolds with homogenous pore size, where a fiber spacing of $500 \mu \mathrm{m}$ produced scaffolds with the smallest pore size and a fiber spacing of $1000 \mu$ m produced scaffolds with the largest pore size analyzed in the RPG and IPG scaffolds. ext, mid, and int refer to the external, middle, and internal regions in the different scaffolds analyzed. 


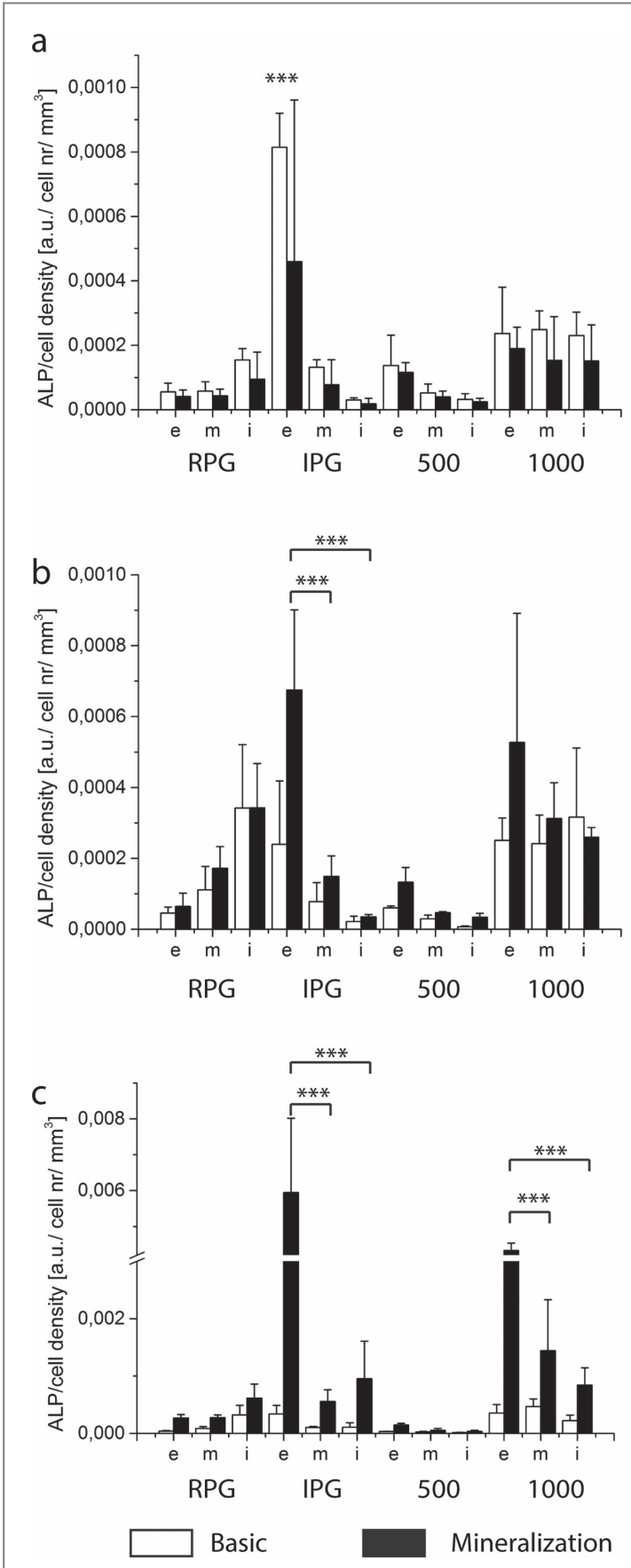

Figure 6. Graphs displaying ALP activity normalized by cell density at $7 \mathrm{~d}$ (a), $14 \mathrm{~d}$ (b) and $28 \mathrm{~d}$ (c), in the different zones of the non-gradient, IPG and RPG scaffolds. ${ }^{* * *}$ statistical significance versus other zones within the same scaffold and under the same conditions, $p<0.001$. In (a), IPGe scaffolds cultured in basic medium showed statistical significance toward all the other conditions and scaffold zones with exception to IPGe scaffolds in mineralization mdium. RPG means radial porosity gradient; IPG means inverted radial porosity gradient; 500 and 1000 refer to scaffolds with homogenous pore size, where a fiber spacing of $500 \mu \mathrm{m}$ produced scaffolds with the smallest pore size and a fiber spacing of $1000 \mu \mathrm{m}$ produced scaffolds with the largest pore size analyzed in the RPG and IPG scaffolds. e, $m$, and i refer to the external, middle, and internal regions in the different scaffolds analyzed.

initial cell seeding density influenced both hMSCs proliferation and differentiation. Dense seeding $\left(8 \times 10^{4}\right.$ cells $\left.\mathrm{cm}^{-2}\right)$ reduced cells proliferation, growth and collagen synthesis whereas it appeared to enhance differentiation markers like ALP activity and mineralization [39]. Consistently with the above mentioned studies, when cell density was also taken into consideration in our studies, the ALP activity was significantly higher in the largest pore size regions (figure 6). Cell migration could represent a possible explanation to these differences between areas: growing inside the scaffold, cells are filling the pores, thus reducing the diffusion of nutrient and oxygen. It might be that limitations in nutrient availability and the consequent hypoxic conditions led hMSCs migration toward the outer part of the scaffold, creating an area of higher cell density near the edges [40]. The controls with the biggest pore size and the RPG scaffolds could be less affected by hMSCs migration because the higher porosity of the central part of the scaffolds might allow better diffusion. Similar trends were also displayed by these scaffolds when cultured in BM, although the level of ALP activity expression were much lower compared to MM. Further investigations need to be performed in order to analyze oxygen and nutrient diffusion inside the different types of scaffold to confirm this hypothesis.

Despite ALP is a widely used marker in osteogenic differentiation of hMSCs, high levels of ALP activity not always correlate with the differentiation toward the osteogenic lineage. Kollmer et al demonstrated that several markers (e.g ALP, collagen type I and osteopontin) currently used to investigate hMSCs differentiation toward the osteogenic lineage are also shared with the adipogenic lineage [41]. In order to understand if the different ALP activity in the areas of the scaffolds corresponded to a heterogeneous hMSCs differentiation, the gene expression of two additional markers was analyzed. Runt-related transcription factor Runx2 is an essential regulator of hMSCs differentiation into the osteogenic lineage [42]. In vitro studies indicated that Runx 2 triggers the expression of major bone protein genes like collagen type I (Col1a1), osteopontin, bone sialoprotein (BSP) and osteocalcin during the early stage of osteoblast differentiation. Therefore, Runx2 lead to mesenchymal cells acquiring an osteoblastic phenotype, inhibiting at the same time the differentiation into adypocytes and chondrocytes. However, it also maintains osteoblastic cells in an immature stage, preventing their maturation and their transition into osteocytes [43]. BSP is a phosphorylated and sulphated glycoprotein that constitutes from $8 \%$ to $12 \%$ of the total non-collagenous proteins in bone. Although BSP function has not been fully characterized yet, its expression is highly specific for mineralizing tissues [44]. After the preliminary screening phase, only IPG was used as control for the gene expression analysis, as ideally it allows monitoring at the same time the contribution of both the variables considered in this study - the pore size and the spatial distribution-on hMSCs differentiation. In both RPG and IPG scaffolds, Runx2 expression decreased after 
Runx2

a

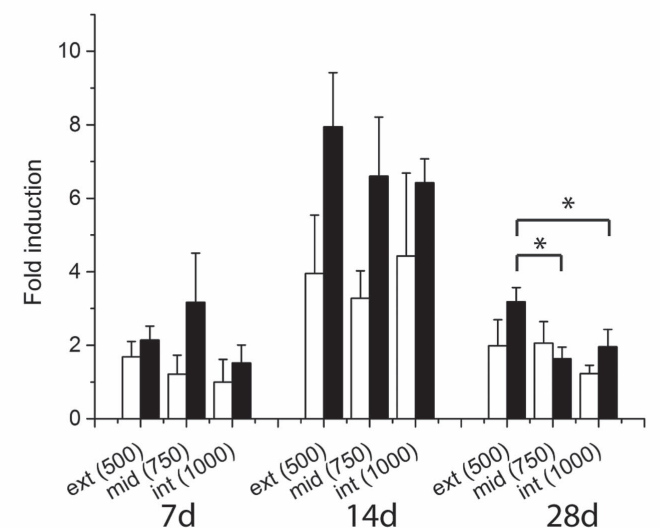

C

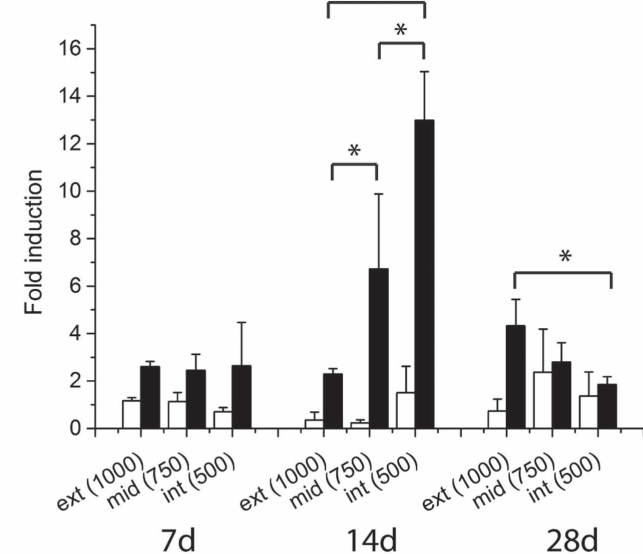

b

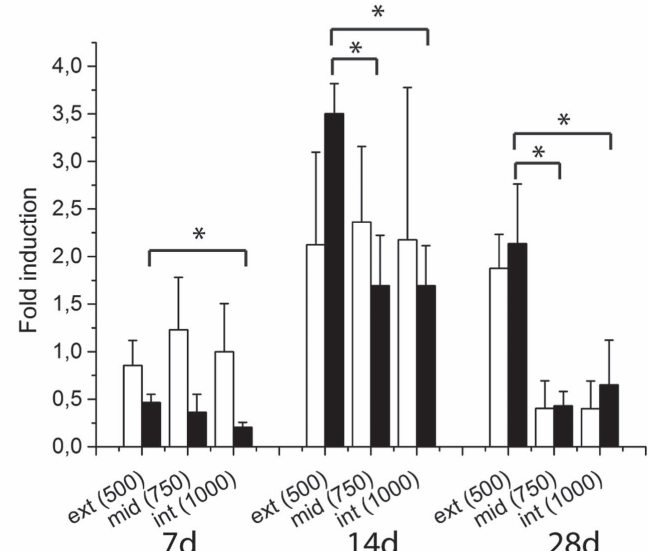

d

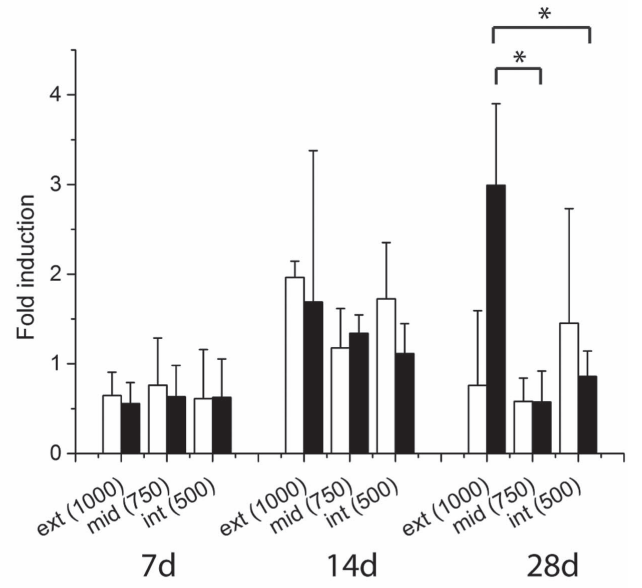

Mineralization

Figure 7. Runx2 and BSP expression in RPG (a) and (b) and IPG (c) and (d) scaffolds. In both types of scaffolds Runx 2 showed the highest upregulation (up to 12 fold induction in the inner part of IPG scaffolds) after $14 \mathrm{~d}$. BSP expression seemed to correlate with Runx2, especially in the RPG scaffolds. * indicates significantly differences $(P<0.05)$ between regions.

$28 \mathrm{~d}$ of culture in MM. This might be associated with a maturation of the osteoblastic phenotype, as it has been proved that Runx 2 expression must be downregulated to mature from pre-osteoblasts to differentiated osteoblasts [45]. BSP upregulation was found consistently with Runx2 upregulation in MM, probably due to the presence OSE2 (osteoblast-specific cisacting element, which is the binding site of Runx2)like elements in the promoter of BSP gene [46]. The late upregulation of Runx 2 and BSP in the outer part of IPG scaffolds might be explained with a delay in hMSCs differentiation in the area with the higher pore volume. The trend showed by the gene analysis highlighted an increased fold induction in the area with smallest pore, independently from their localization within the scaffold. Since from the ALP and gene analysis, hMSCs seemed to be proceeding toward a mature osteogenic differentiation, a late markers analysis was performed. EDX and alizarin red staining were used to analyze the mineralization of the ECM matrix. During bone mineralization, transient amorphous calcium phosphates and poorly crystalline apatite are formed. Later, these precursors undergo several crystalline phase transitions before the more stable crystalline hydroxyapatite (HA) finally forms. Anionic proteins attached to collagen are believed to be responsible for the stabilization of amorphous calcium phosphate in the early stage of bone mineralization, and the subsequent formation of nanometersized particles [47]. Early stage of mineralized calcium phosphate deposits could be found in RPG scaffolds in MM culture conditions (figure 7). The identification of these firsts mineralization nodules represented a clear evidence of late hMSCs maturation toward the osteoblastic phenotype [48]. Despite EDX is not ideal for making definitive statements about the stoichiometry of calcium phosphates on gold-coated samples since gold will confound the EDX phosphorus signal, the atomic spectrum together with the Alizarin Red images were clear indicators that hMSCs have deposited calcium and phosphate on the scaffold's surface [49]. SEM analysis further confirmed that the pore 


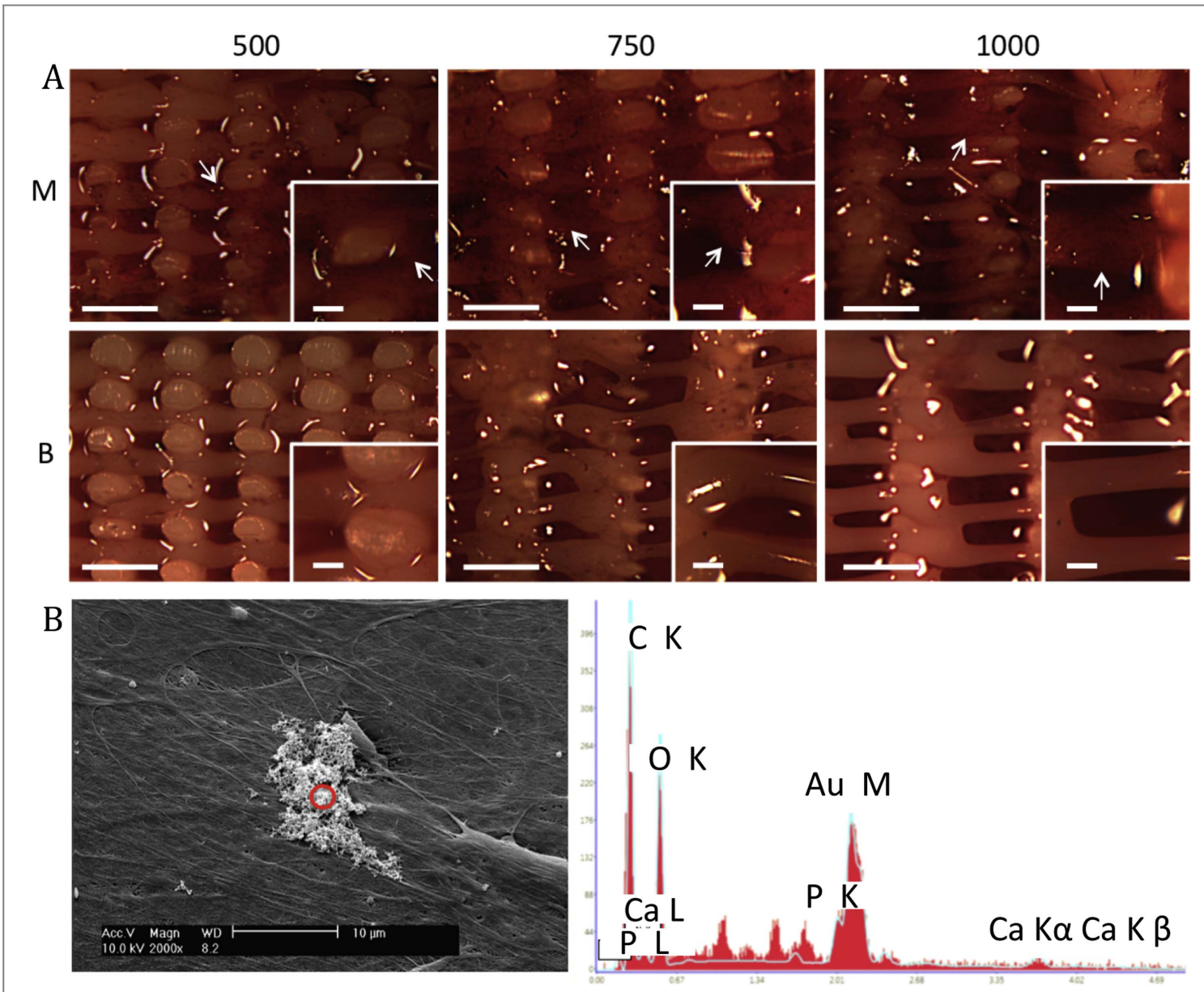

Figure 8. Calcium phosphate presence confirmed by alizarin red staining (A) and SEM-EDX analysis (B). White arrows (A) indicate the presence of calcium on the matrix. Only few deposit were seen in cells after $28 \mathrm{~d}$ of culture in BM. Scale bars represent in the main pictures $500 \mu \mathrm{m}$ and in the insertion $100 \mu \mathrm{m}$. SEM image (B) shows a mineralization nodule. The EDX analysis confirmed the presence of both calcium and phosphate.

closure process started earlier and proceeded faster in the scaffold with the smallest porosity. Therefore, the earlier differentiation of these areas could be associated with the earlier reaching of a $3 \mathrm{D}$ confluence. Even though in the areas with a bigger pore size the pores were not completely closed by the bridging hMSCs, a more homogeneous tissue ingrowth was observed especially in the outer and middle part of the IPG scaffolds. In contrast with these observations, in the areas with the smallest pore size cells appeared to be more confluent in some part of the scaffolds but less homogeneously distributed. Similar results were obtained also by Mygind et al [50]. These findings could provide a possible explanation for the absence of differences in cell densities between the control scaffolds and among their three areas. Therefore, it is plausible that, even though the cell number in the different area was the same, their spatial distribution affected their density locally, which could have promoted hMSCs differentiation. It was proved that cadherins and cell-cell gap junctions are required for full expression of the osteoblastic phenotype. For this reason it is thought that a higher cell density, which finally resulted in a higher degree of cell-cell communication, could lead to a higher rate of differentiation [51].

Although cell density seemed to supply a possible explanation for the collected data, other factors could have contributed to influence hMSCs behavior. Several studies showed that hMSCs differentiation could be affected by hypoxia, as under hypoxic condition the degradation of HIF- $1 \alpha$ is prevented. This finally leads to the induction of pluripotent genes like Oct- 4 and klf- 4 and to the inhibition of cell terminal differentiation [52]. It is possible that the cells in the inner part of the scaffolds and in the areas with a lower pore volume are under hypoxic condition as the oxygen and the nutrient diffusion is affected by the pore closure during the culture time [53]. Therefore, a more in depth analysis of the cause of this different hMSCs behavior related to the different pore size is required to assess whether cell density or local availability of oxygen could be the cause of the observed influence of pore size on hMSCs osteogenic differentiation. Further studies should also aim at understanding if these results are dependent only from the structural radial gradient, or also from the chemical composition of the scaffolds. From our previous experience with axial gradients, the 
effect of pore size gradients on hMSCs osteogenic differentiation was evident on both PEOT/PBT as well as PCL scaffolds [29]. Therefore, we could speculate that also in case of radial gradients the effect of structural properties may be predominant over the chemical composition of the scaffolds. Despite a further confirmation of these promising in vitro studies should be performed with more hMSCs donors and in preclinical animal models, engineering structural radial gradients in 3D scaffolds could be an appealing new strategy to support adult stem cell driven bone regeneration.

\section{Conclusions}

A scaffold with an in-built radial interconnected porosity gradient was fabricated. To evaluate if hMSCs behavior could be affected by the porosity and pore size of RPG scaffolds, several markers were investigated. ALP activity showed a higher activity in the areas with the larger pore size both in the RPG and IPG scaffolds when the pore architecture is taken into consideration. However, ALP activity seemed also to be dependent from the geometric location (inside vs outside) of the pore region when cellular activity is analyzed. These evidences suggested that the pore size and location could influence hMSCs differentiation toward the osteoblastic phenotype. Runx-2 and BSP gene upregulation, with higher fold change in the regions with the smaller pore volume, further confirmed hMSCs differentiation toward the osteogenic lineage. To have a better understanding of the maturation stage of hMSCs, a mineralization staining was performed, which highlighted the presence of calcium phosphate deposits. The presence of colocalized calcium and phosphate was confirmed through point analyses by EDX. A possible explanation for this different hMSCs behavior can be related to the different cell density according to the different pore sizes in the internal, middle, and external regions of RPG scaffolds. Therefore, tailoring scaffolds' pore size might be a good strategy to affect hMSCs osteogenic differentiation.

\section{Acknowledgments}

We are grateful to the Dutch Technology Foundation (STW, grant \#11135) for financial support. This project/research was also possible thanks to the Dutch province of Limburg.

\section{References}

[1] Carter G 1999 Harvesting and implanting allograft bone AORNJ. 70 660-70

[2] Ilan D I and Ladd A L 2002 Bone graft substitutes Operative Tech. Plast. Reconstructive Surg. 9 151-60

[3] Giannoudis P V, Dinopoulos H and Tsiridis E 2005 Bone substitutes: an update Injury 36 (Suppl 3) S20-7
[4] Conrad E U et al 1995 Transmission of the hepatitis-C virus by tissue transplantation J. Bone Joint Surg. Am. 77 214-24

[5] Giannoudis P V et al 2011 What should be the characteristics of the ideal bone graft substitute? Injury 42 (Suppl 2) S1-2

[6] Harris L D, B-S K and Mooney D J 1998 Open pore biodegradable matrices formed with gas foaming J. Biomed. Mater. Res. 42 396-402

[7] Salerno A, Iannace S and Netti P A 2012 Graded biomimetic osteochondral scaffold prepared via $\mathrm{CO} 2$ foaming and micronized $\mathrm{NaCl}$ leaching Mater. Lett. 82 137-40

[8] Levingstone T J et al 2014 A biomimetic multi-layered collagen-based scaffold for osteochondral repair Acta Biomater. 10 1996-2004

[9] Sin D et al 2010 Polyurethane (PU) scaffolds prepared by solvent casting/particulate leaching (SCPL) combined with centrifugation Mater. Sci. Eng.: C 30 78-85

[10] Suh S W et al 2002 Effect of different particles on cell proliferation in polymer scaffolds using a solvent-casting and particulate leaching technique ASAIO J. 48 460-4

[11] Hutmacher D W 2000 Scaffolds in tissue engineering bone and cartilage Biomaterials 21 2529-43

[12] Zein I, D W H, Tan K C and Teoh S H 2002 Fused deposition modeling of novel scaffold architectures for tissue engineering applications Biomaterials 23 1169-85

[13] Bianco P and Robey P G 2001 Stem cells in tissue engineering Nature 414 118-21

[14] Williams J T et al 1999 Cells isolated from adult human skeletal muscle capable of differentiating into multiple mesodermal phenotypes Am. Surg. 65 22-6

[15] Bruder S P, Jaiswal N and Haynesworth S E 1997 Growth kinetics, self-renewal, and the osteogenic potential of purified human mesenchymal stem cells during extensive subcultivation and following cryopreservation J. Cell Biochem. 64 278-94

[16] Augello A and De Bari C 2010 The regulation of differentiation in mesenchymal stem cells Hum. Gene Therapy 21 1226-38

[17] Tse J R and Engler A J 2011 Stiffness gradients mimicking in vivo tissue variation regulate mesenchymal stem cell fate PLoS One 6 e 15978

[18] Park J S et al 2011 The effect of matrix stiffness on the differentiation of mesenchymal stem cells in response to TGFbeta Biomaterials 32 3921-30

[19] Kilian K A et al 2010 Geometric cues for directing the differentiation of mesenchymal stem cells Proc. Natl Acad. Sci. $1074872-7$

[20] Kasten P et al 2008 Porosity and pore size of beta-tricalcium phosphate scaffold can influence protein production and osteogenic differentiation of human mesenchymal stem cells: an in vitro and in vivo study Acta Biomater. 4 1904-15

[21] Chen G, Deng C and Li Y-P 2012 TGF- $\beta$ and BMP signaling in osteoblast differentiation and bone formation Int. J. Biol. Sci. 8 272-88

[22] Re'em T et al 2012 Simultaneous regeneration of articular cartilage and subchondral bone induced by spatially presented TGF-beta and BMP-4 in a bilayer affinity binding system Acta Biomater. $83283-93$

[23] Reyes Ret al 2014 Repair of an osteochondral defect by sustained delivery of BMP-2 or TGFbeta1 from a bilayered alginate-PLGA scaffold J. Tissue Eng. Regen. Med. 8 521-33

[24] Bose S, Roy M and Bandyopadhyay A 2012 Recent advances in bone tissue engineering scaffolds Trends Biotechnol. 30 546-54

[25] Guarino V, Causa F and Ambrosio L 2007 Bioactive scaffolds for bone and ligament tissue Expert Rev. Med. Devices 4 405-18

[26] Salgado A J, Coutinho O P and Reis R L 2004 Bone tissue engineering: state of the art and future trends Macromol. Biosci. 4743-65

[27] Hou Q, Grijpma D W and Feijen J 2003 Porous polymeric structures for tissue engineering prepared by a coagulation, compression moulding and salt leaching technique Biomaterials 24 1937-47

[28] Sikavitsas V I, Temenoff J S and Mikos A G 2001 Biomaterials and bone mechanotransduction Biomaterials 22 2581-93 
[29] Di Luca A et al 2016 Gradients in pore size enhance the osteogenic differentiation of human mesenchymal stromal cells in three-dimensional scaffolds Sci. Rep. 622898

[30] Landers Ret al 2002 Fabrication of soft tissue engineering scaffolds by means of rapid prototyping techniques J. Mater. Sci. 37 3107-16

[31] Miao X and Sun D 2009 Graded/gradient porous biomaterials Materials 3 26-47

[32] Oh S H et al 2007 In vitro and in vivo characteristics of PCL scaffolds with pore size gradient fabricated by a centrifugation method Biomaterials 28 1664-71

[33] Tampieri A et al 2001 Porosity-graded hydroxyapatite ceramics to replace natural bone Biomaterials 22 1365-70

[34] Sobral J M et al 2011 Three-dimensional plotted scaffolds with controlled pore size gradients: effect of scaffold geometry on mechanical performance and cell seeding efficiency Acta Biomater. 7 1009-18

[35] Woodfield T B et al 2005 Polymer scaffolds fabricated with pore-size gradients as a model for studying the zonal organization within tissue-engineered cartilage constructs Tissue Eng. 11 1297-311

[36] Di Luca A et al 2016 Influencing chondrogenic differentiation of human mesenchymal stromal cells in scaffolds displaying a structural gradient in pore size Acta Biomater. 36 210-9

[37] Leferink A M et al 2013 Increased cell seeding efficiency in bioplotted three-dimensional PEOT/PBT scaffolds J. Tissue Eng. Regen. Med. 10 679-89

[38] Pfister A et al 2004 Biofunctional rapid prototyping for tissueengineering applications: $3 \mathrm{D}$ bioplotting versus $3 \mathrm{D}$ printing J. Polym. Sci. A 42 624-38

[39] Goldstein A S 2001 Effect of seeding osteoprogenitor cells as dense clusters on cell growth and differentiation Tissue Eng. 7 817-27

[40] Dunn J C et al 2006 Analysis of cell growth in threedimensional scaffolds Tissue Eng. 12 705-16

[41] Kollmer M et al 2013 Markers are shared between adipogenic and osteogenic differentiated mesenchymal stem cells J. Dev. Biol. Tissue Eng. 5 18-25
[42] Komori T et al 1997 Targeted disruption of Cbfal results in a complete lack of bone formation owing to maturational arrest of osteoblasts Cell $89755-64$

[43] Komori T 2006 Regulation of osteoblast differentiation by transcription factors J. Cell Biochem. 99 1233-9

[44] Bianco P et al 1991 Expression of bone sialoprotein (BSP) in developing human tissues Calcif. Tissue Int. 49 421-6

[45] Liu W et al 2001 Overexpression of Cbfal in osteoblasts inhibits osteoblast maturation and causes osteopenia with multiple fractures J. Cell Biol. 155 157-66

[46] Tu Q et al 2008 Haploinsufficiency of Runx2 results in bone formation decrease and different BSP expression pattern changes in two transgenic mouse models J. Cell Physiol. 217 $40-7$

[47] Song J, Malathong V and Bertozzi C R 2005 Mineralization of synthetic polymer scaffolds: a bottom-up approach for the development of artificial bone J. Am. Chem. Soc. 127 3366-72

[48] Huang W et al 2007 Signaling and transcriptional regulation in osteoblast commitment and differentiation Front Biosci. 12 3068-92

[49] Ruckh T T et al 2010 Osteogenic differentiation of bone marrow stromal cells on poly(epsilon-caprolactone) nanofiber scaffolds Acta Biomater. 62949-59

[50] Mygind T et al 2007 Mesenchymal stem cell ingrowth and differentiation on coralline hydroxyapatite scaffolds Biomaterials 28 1036-47

[51] Schiller P Cet al 2001 Gap-junctional communication is required for the maturation process of osteoblastic cells in culture Bone 28 362-9

[52] Buravkova L B et al 2014 Mesenchymal stem cells and hypoxia: Where are we? Mitochondrion 19 Pt A 105-12

[53] Karande T S, Ong J L and Agrawal C M 2004 Diffusion in musculoskeletal tissue engineering scaffolds: design issues related to porosity, permeability, architecture, and nutrient mixing Ann. Biomed. Eng. 32 1728-43 